Brit. J. vener. Dis. (1965), 41, 181.

\title{
CARDIOVASCULAR SYPHILIS WITH AMYLOIDOSIS AND PERIODS OF ALTERNATING HEART BLOCK*
}

\author{
BY
}

GEORGE MASTERTON

Royal Infirmary, Edinburgh

During the past 50 years amyloidosis has become a disease of comparative rarity in Great Britain. Tuberculosis and chronic bone disease-long recognized as the main precursors of amyloidosisrespond so well to improved surgical techniques and antibiotic therapy that they no longer pursue the protracted course which so often brought amyloid disease in its train. Many of the older textbooks of pathology list tertiary syphilis as the third most common condition to predispose towards amyloidosis, though very few fully-documented cases of this type can be found in the literature (Kellogg, 1953). However, the following seems to be an undeniable example of generalized amyloidosis secondary to cardiovascular syphilis. The interchanging pattern of left then right bundle branch block and the diversity of the cardiac lesions found at necropsy are additional points of interest.

\section{Case Report}

A married seaman aged 51 years was first seen on February 13, 1956, when he had been off work for 4 weeks suffering from dysuria and diurnal frequency of micturition. He had also breathlessness on moderate exertion and had occasionally noticed sharp stabbing pains in the region of the left scapula. From the onset of his illness he had been under the care of his general practitioner who had noted the presence of "marked albuminuria with a slow radial pulse". As routine serological tests for syphilis (Wassermann and Kahn reactions) had proved positive, he was referred to the clinic for an opinion.

Examination.-He was pale with slight cyanosis of the lips. Moderate pitting oedema of both feet and ankles was present. The heart was enlarged to the left side-apex beat in sixth interspace $\frac{1}{2}$ " outside midclavicular lineforcible impulse. The right heart border was percussed $\frac{1}{2}$ " outside of the right lateral sternal line at level of the fourth rib. On auscultation soft systolic and diastolic

* Received for publication March 15, 1965. murmurs were heard at the cardiac apex. The radial pulse was slow ( 40 beats per minute) but regular in time and force. Blood pressure readings were 140/65. Retinal blood vessels were normal. No adventitial sounds were heard in the lungs. The abdomen was soft, moved well on respiration, and no ascites was apparent. The liver, enlarged 1 to 2 finger breadths below the costal margin, was smooth, firm, and not tender. The spleen and kidneys were not palpable. No abnormality was detected in the central nervous system. No scars suggestive of previous syphilitic infection were seen on the genitalia or elsewhere on the body. The urine was pale, specific gravity 1014 , with gross proteinuria. The patient was admitted to hospital for fuller examination.

\section{Further Investigations}

(a) Cardiovascular System.-Radiological examination confirmed the presence of a considerable degree of generalized cardiac enlargement (transverse diameter $200 \mathrm{~mm}$.) and both ventricles were involved in this process. The aortic arch was unfolded but no calcification was seen-nor did there appear to be any aneurysmal formation. Electrocardiography showed complete heart block with a ventricular rate of 46 beats per minute. Left bundle branch block was also noted.

(b) Biochemical Investigations.-Hb 85 per cent. Red blood cells 4,200,000/c.mm.; white blood cells 7,800/ c.mm. Erythrocyte sedimentation rate $97 \mathrm{~mm} . / 1 \mathrm{hr}$ : $118 \mathrm{~mm} . / 2 \mathrm{hrs}$. Blood urea $18 \mathrm{mg}$./100 ml. Plasma albumin 1.6 g./100 ml. Plasma globulin $2.6 \mathrm{~g} . / 100 \mathrm{ml}$. Nonprotein nitrogen $25 \mathrm{mg}$. $/ 100 \mathrm{ml}$.

Serum electrophoresis: total protein $5 \mathrm{~g} . / 100 \mathrm{ml}$; albumin 1.1 g./100 ml., $\alpha$ globulin 0.2 g. $/ 100 \mathrm{ml}$, $\alpha_{2}$ globulin $1.9 \mathrm{~g} . / 100 \mathrm{ml}$., $\beta$ globulin $0.6 \mathrm{~g} . / 100 \mathrm{ml}$., $\gamma$ globulin $1.2 \mathrm{~g} . / 100 \mathrm{ml}$. Serum sodium $341 \mathrm{mg} . / 100 \mathrm{ml}$. Serum potassium $18.1 \mathrm{mg} . / 100 \mathrm{ml}$. Serum chloride $600 \mathrm{mg}$. $/ 100 \mathrm{ml}$. Serum calcium $8.7 \mathrm{mg}$./100 ml. Plasma cholesterol $272 \mathrm{mg} . / 100 \mathrm{ml}$. Plasma inorganic phosphorus $3.6 \mathrm{mg} . / 100 \mathrm{ml}$.

Liver function tests were within normal limits, but the Congo red absorption test (done on February 29 and 
April 5, 1956) gave positive readings with over 80 per cent. absorption of the dye within 1 hour.

Proteinuria.-Using the Esbach albuminometer, daily readings showed an albumin content ranging between $7 \cdot 5$ and $12 \mathrm{~g}$./litre. On culture of the urine no growth was obtained. Centrifuged deposits contained a few pus cells and red blood cells with occasional hyaline casts.

\section{(c) Serological Tests for Syphilis}

Standard Wassermann reaction: positive

Price's precipitation test: positive $1 / 512$ dilution

Routine Kahn reaction: positive

Quantitative Wassermann reaction: 32 units positive

Treponemal immobilization test: positive 100 per cent. immobilization

Cerebrospinal fluid: 1 cell $/$ c.mm. Protein, 30mg. per cent. Globulin, no increase

Wassermann reaction, $0 \cdot 1 \mathrm{ml}$. negative, $0.5 \mathrm{ml}$. weak positive, $1.0 \mathrm{ml}$. strongly positive Lange gold curve, 1111000000

(d) Biopsy.-No amyloid infiltration was found in specimens taken from the gingival margins.

Diagnosis.-At this stage the tentative diagnosis was one of amyloidosis with an associated nephrotic syndrome. The relationship, if any, between the heart block and the late syphilitic infection had still to be clarified.

Treatment.-To compensate for the constant proteinuria a high protein and salt-restricted diet was given together with "Complan". The oedema was treated with Mersalyl $1 \mathrm{ml}$. intramuscularly twice-weekly. Later this régime was replaced by Mictine tablets $200 \mathrm{mg}$. four times a day on alternate days.

Treatment for syphilis commenced with potassium iodide $10 \mathrm{gr}$. three times a day for 3 weeks followed by procaine penicillin $(600,000$ units daily) to a total of 22 mega units.

An electrocardiogram tracing taken 2 days after this course was completed was most interesting: "Complete heart block persists. In the standard leads and in a VR and a VL the pattern remains as before-left bundle branch block. There is a curious change, however, in a VF and in the chest leads, where the pattern of ventricular complexes is now that of right bundle branch block. It is most probable that this alteration in conduction occurred during the taking of the record".

Before discharge from hospital he was given a further 10 mega units penicillin.

Condition on Discharge from Hospital.-On April 27, 1956, he had no cyanosis or oedema of the lower extremities. The heart block persisted but had reverted to the original left bundle branch block pattern. Blood pressure $160 / 80$. The proteinuria persisted at the level of 5 g./litre (Esbach). Erythrocyte sedimentation rate
$24 \mathrm{~mm} . / 1 \mathrm{hr}: 30 \mathrm{~mm} . / 2 \mathrm{hrs}$. Plasma albumin $2 \cdot 5$ g. $/ 100$ $\mathrm{ml}$. Plasma globulin $2 \cdot 1 \mathrm{~g}$. $/ 100 \mathrm{ml}$. Non-protein nitrogen $30 \mathrm{mg} . / 100 \mathrm{ml}$. The serological tests for syphilis all remained positive although the quantitative Wassermann was now 16 units positive.

\section{Follow-up}

First Year (ending April 1, 1957).-The general condition was satisfactory with very little dyspnoea and no oedema; the heart block showed an interesting change in pattern:

June, 1956: electrocardiogram report: "The complete heart block still persists but the left bundle block has disappeared. There is one complex in V2 which suggests that there may be a right bundle branch block. A shifting heart block has previously been found in this patient".

October, 1956.-Electocardiogram report: "Persistence of complete heart block. There is now complete right bundle branch block whereas previously there was complete left bundle branch block. Auricular rate $88 / \mathrm{min}$.: ventricular rate $38 / \mathrm{min}$."

Radiology.-Gross cardiac enlargement with an increased transverse diameter-208 $\mathrm{mm}$. as compared with a previous $200 \mathrm{~mm}$.

Blood pressure $160 / 85$. Erythrocyte sedimentation rate within normal limits. Haemoglobin 86 per cent. Plasma albumin 2.5 g. $/ 100 \mathrm{ml}$. Plasma globulin $2.3 \mathrm{~g} . / 100 \mathrm{ml}$. Non-protein nitrogen $36 \mathrm{mg} . / 100 \mathrm{ml}$. Thus the albumin/ globulin ratio was approaching normal levels although the albumin fraction was still showing low readings.

Proteinuria.-Still present, averaging around 3 g./litre (Esbach).

Standard serological tests for syphilis.-Remained strongly positive, quantitative Wassermann reaction 16 units.

\section{Cerebrospinal fluid findings.-_Reverted to normal.}

Under a penicillin "screen", total extraction of the patient's carious teeth was performed. Further treatment was required for boils, etc., and a further 40 mega units penicillin were given during the year.

The high protein diet with added Casilan supplement was continued. The oedema was controlled with Mictine tablets $200 \mathrm{mg}$. four times a day on alternate days.

Second Year (ending April 1, 1958).-The general condition remained satisfactory although he was still dyspnoeic on moderate exertion. The liver no longer showed clinical enlargement. On occasions his feet and ankles showed oedema yet he was able to seek-and keepa light job. The clinical findings were as before with the electrocardiogram still showing right bundle branch block. The serum albumin/globulin ratio approached normal. Proteinuria still continued in the region of 3 g./litre (Esbach's albuminometer). The high protein 
diet with supplement was continued and chlorothiazide $1 \mathrm{~g}$. daily controlled the oedema.

Third Year (ending April 1, 1959).-The general condition was not so satisfactory and the legs were oedematous at every examination. Nevertheless he was able to continue light work with little inconvenience. The electrocardiograph and radiological reports showed no change. Blood chemistry gave almost normal values for the albumin/globulin serum ratio. Treatment continued along the usual lines although the chlorothiazide was increased to $2 \mathrm{~g}$. daily to control the oedema.

Fourth Year (ending February, 1960).-He attended as an out-patient in July and December of the year 1959. His health was remarkably good and he was still able to work a full day. The blood chemistry, $x$-ray, and electrocardiograph findings were unchanged.

Terminal Admission.-The patient was admitted to hospital in extremis on February 2, 1960. For the past few weeks he had been bedfast, progressively losing ground, and "vomiting up blood". He was disorientated and difficult to manage. He had extreme dyspnoea with deep cyanosis of the lips. There were clear signs of circulatory collapse but the extremities were not oedematous. The radial pulse was weak, thready, and irregular, rate 40 beats per minute. Blood chemistry showed plasma albumin $3.4 \mathrm{~g}$. $/ 100 \mathrm{ml}$.; plasma globulin $2.7 \mathrm{~g} . / 100 \mathrm{ml}$. Blood urea $276 \mathrm{mg}$. $/ 100 \mathrm{ml}$. He failed to respond to the usual measures and died one hour after admission.

\section{Post Mortem Report}

"No free fluid was found in the peritoneal or pleural sacs. The pericardial sac was obliterated by dense adhesions in keeping with an organized pericarditis. The heart ( $650 \mathrm{~g}$.) was globular in shape and firm with an old myocardial infarction in the posterior wall. A gumma was found in the region of the interseptal bundle. This presented as an amorphous acidophil area with round cell infiltration and endarteritis at the margins. Necrosis and calcification was taking place in the central zone of the gumma. The heart valves were competent and the cusps were free from disease. The coronary ostia were narrowed from involvement in the syphilitic scarring in the aorta.

Aorta: Numerous atheromatous plaques and many small pearly-white scar areas suggestive of a syphilitic aortitis.

Liver (1,975 g.) showed early chronic venous congestive changes. On histological examination small quantities of amyloid tissue were found in the periphery of the hepatic lobules.

Spleen $(180 \mathrm{~g}$.): The capsule was thickened in places, the appearances being in keeping with old subcapsular haemorrhage. Small quantities of amyloid tissue were found in the sinusoids of the organ.

Kidneys (right 250 g.; left 250 g.): The capsules stripped easily, revealing pale granular kidneys with one or two small scars suggesting healed infarcts. Histologically amyloid tissue was seen in the endothelial lining of the smaller blood vessels and in many of the glomerular tufts.

\section{Discussion \\ (1) Generalized Amyloidosis}

The postmortem demonstration of amyloid tissue has always been relatively simple either histologically or macroscopically after preliminary staining with certain basic aniline dyes. Paradoxically, the diagnosis of the condition during life is a matter of extreme difficulty. The clinical picture is frequently as ill-defined as it is variable -depending, as it does upon the particular organ involved and the extent to which the infiltrative process interferes with the normal functioning of the affected tissue. Indeed, amyloidosis is often only suspected because of the presence of some other long-standing pathological process with which it has known associations.

Throughout the years there has been a constant search for some means of assisting the clinician in his quest for an early diagnosis during life. The first steps in this direction were taken when it was observed that in the living patient amyloid tissue could remove, and be stained by, Congo red circulating in the blood stream. As normal healthy individuals also absorbed the dye to some extent, Bennhold (1923) suggested that the standard for a positive reading should be at least 60 per cent. absorption of the dye from the blood stream within 1 hour $(15 \mathrm{ml}$. of an $\mathbf{0 . 7 5}$ per cent. solution of Congo red injected intravenously). This was a purely quantitative test and so numerous other workers elaborated and varied the method and their cumulative findings seemed to suggest that this Congo red test was a valuable aid to diagnosis. It is now possible to view the test in its correct perspective and it has been found to be unreliable and often misleading. In general, however, any discrepancy is on the side of under-diagnosis i.e. false negative readings, although false positive results have been recorded (Lipstein, 1938).

Although the pathogenesis of amyloid disease remains obscure, there is a strong belief that some chronic disorder of protein metabolism may be involved (Cohen, 1943) or alternatively that there is some protein-like circulating precursor which by a process of polymerization is converted to amyloid tissue extravascularly (Lancet, 1961). Hence many workers have sought for possible diagnostic significance in repeated protein serum estimations. In this connexion, a relative increase in the globulin fraction has been recorded on more than one occasion (Reimann and Eklund, 1935). However, further investigations along these lines have shown that such estimations were too unreliable to be of diagnostic significance. Nor have the new electrophoretic serum values shed new light on the subject. Blood protein estimations would therefore seem to be of prognostic rather than diagnostic import.

Recently biopsy has become the preferred method of diagnosis. Since the liver and spleen were known to be involved in most cases of generalized amyloidosis, these 
were the organs most frequently selected for examination, with extremely satisfactory results. However, many clinicians disliked this "blind" approach and, as amyloidosis is a generalized condition with widespread deposition of typical material, a search was made for more easily accessible and safer sites for biopsy. Unfortunately, it seemed that such safety could be gained only at the expense of accuracy, as the "unorthodox" sites yielded comparatively poor results. This picture was drastically altered by the findings of Blum and Sohar (1962); in a series of 200 patients they showed that rectal biopsy gave results which compared very favourably with those from the liver and kidneys. The gingival biopsy suggested by Selikoff and Robitzek (1946) seemed unreliable. Blum and Sohar concluded that rectal biopsy should be the first step in any attempted diagnosis of amyloidosis.

Applying the above diagnostic criteria to our patient, the Congo red test, with a reading of over 80 per cent. absorption within 1 hour, was regarded as strongly suggestive. The blood protein estimations showed a definite alteration in the albumin/globulin ratio-the albumin fraction being much reduced. The electrophoretic findings confirmed this decrease in albumin whilst showing a pronounced rise in the $\alpha_{2}$ globulin fraction. Neither of these findings is specific for amyloidosis, for they occur whenever there is gross proteinuria, particularly in the nephrotic syndrome whatever the aetiology of the latter. In view of the findings of Blum and Sohar (1962), the negative gingival biopsy can only be regarded as inconclusive. With the wisdom of hindsight, it is clear that a rectal biopsy would have been preferable.

$\mathrm{Be}$ that as it may, the positive Congo red test, associated with hypoalbuminaemia, gross proteinuria, polyuria, hepatomegaly, and normal blood pressure readings, prompted a fairly confident clinical diagnosis of generalized amyloidosis. This opinion was vindicated post mortem, when the features of the so-called classical secondary amyloidosis were demonstrated. The distribution of amyloid tissue affected the glomerular tufts of the kidneys, the sinusoids of the spleen, and the periphery of the hepatic lobules. The intima and inner layers of the media were the sites of the amyloid deposition-a distribution which invariably occurs in secondary amyloidosis according to Missmahl (1959). Likewise it corresponds to the typical reticular distribution of Gafni (1962), who also related it to classical secondary amyloid disease.

The scanty amount of amyloid tissue present in the liver is surprising. In view of the positive Congo red test some four years previously, one might reasonably suppose that the liver was at that time the seat of considerable infiltration. It therefore seems probable that with the treatment of the syphilitic condition some regression of the amyloidosis did take place.

\section{(2) Cardiovascular Syphilis}

Autopsy confirmed that the cardiovascular system had borne the brunt of an extensive syphilitic attack. The aortitis had been diagnosed and the gumma had been suspected during the patient's lifetime but the pericarditis and the old myocardial infarction were totally unexpected findings. The infarction was almost certainly secondary to the syphilitic involvement of the coronary ostia but the cause of the adherent pericarditis was obscure. It could have been a sequel to the myocardial infarction-a not uncommon occurrence, although such pericarditis is usually localized. However, in 15 per cent. of such patients, the disease process becomes generalized and can terminate in the adherent type of pericarditis (Wood, 1956). A syphilitic pericarditis per se is nowadays regarded as exceedingly rare, in complete contrast to the earlier views of Brooks (1913). A third possibility was that the pericarditis could have been an expression of the reduced resistance to bacterial invasion commonly found in the nephrotic patient. Unfortunately histological study failed to clarify the position. The most feasible explanation would be that the pericarditis did follow the myocardial infarction, which in turn was due to the syphilitic involvement of the orifices of the coronary arteries.

A bizarre finding was the alternating patterns of left then right bundle branch block. This was due to the presence of a gummatous lesion, in the interventricular septum in close proximity to the bifurcation of the atrioventricular bundle. The variable pressure-affecting first one fasciculus then the other -was due to the alteration during treatment of the size of the lesion as it passed through the phases of necrosis and partial calcification. It is fortunate that cardiac gummata are rare since they generally occur in this critical area.

An intriguing problem was the generalized cardiac hypertrophy which occurred in the absence of demonstrable hypertension or valvular lesions. Until recently, it was believed that adherent pericarditis could cause such hypertrophy as a result of the heart pulling against tethering adhesions. However, later experimental and clinical studies have effectively disproved this theory and adherent pericarditis is no longer regarded as a possible cause of cardiac embarrassment (Cecil and Loeb, 1959).

In our patient there were no adhesions between the pericardial sac and the other mediastinal structures. Thus it seems that the adherent pericarditis could not have caused the cardiac hypertrophy. However, in heart block, the slow rate leads to prolonged diastolic filling with dilatation of the chambers. To distribute the increased volume of systolic blood, compensatory hypertrophy of the cardiac musculature takes place. As might be expected, the left side of the heart is chiefly affected and marked hypertrophy of the left ventricle occurs, 
This was precisely what happened in our patient. In life there had been a considerable increase in the transverse diameter of the heart, and at autopsy the organ was about twice the average weight. It seems reasonable to conclude that the cardiac dilatation and hypertrophy were secondary to the prolonged heart block.

\section{Summary}

(1) The clinical features, laboratory investigations, and autopsy report of a case of cardiovascular syphilis with amyloidosis are described.

(2) The difficulty in diagnosing amyloidosis with certainty in the living patient is discussed, and recent progress in this field, with particular reference to rectal biopsy, is noted.

(3) An attempt is made to correlate the cardiac picture as seen on clinical examination with that of the necropsy report, special emphasis being given to the rare alternating bundle branch block and the cardiac hypertrophy.

This patient was under the care of Dr Robert Lees, to whom I am grateful for help and advice in the preparation of this report.

\section{REFERENCES}

Bennhold, H. (1923). Dtsch. Arch. klin. Med., 142, 32. Blum, A., and Sohar, E. (1962). Lancet, 1, 721.

Brooks, H. (1913). Amer. J. med. Sci., 146, 513.
Cecil, R. L., and Loeb, R. F. (1959). "A Textbook of Medicine", p. 1211. Saunders, Philadelphia.

Cohen, S. (1943). Ann. intern. Med., 19, 990.

Gafni, J. (1962). Proc. Tel-Hashomer Hosp., 1, 73.

Kellogg, C. S. (1953). Ohio med. J., 49, 413.

Lancet (1961). 1, 1215. (Annotation).

Lipstein, S. (1938). Amer. J. med. Sci., 195, 205.

Missmahl, H. P. (1959). Verh. dtsch. Ges. inn. Med., 65, 439.

Reimann, H. A., and Eklund, C. M. (1935). Amer. J. med. Sci., 190, 88 .

Selikoff, I. J., and Robitzek, E. H. (1946). Quart. Bull. Sea View Hosp., 8, 310.

Wood, P. (1956). "Diseases of the Heart and Circulation", 2nd ed., p. 678. Eyre and Spottiswoode, London.

Syphilis cardiovasculaire avec dégénérescence amyloïde et bloc cardiaque partiel du type $2 / 1$.

\section{RÉSUMÉ}

(1) On décrit les symptômes cliniques, les examens de laboratoire et l'autopsie d'un cas de syphilis cardiovasculaire avec dégénérescence amyloïde.

(2) On discute la difficulté d'un diagnostic certain de la syphilis chez le malade pendant la vie et on mentionne les progrès récents faits dans ce domaine, spécialement en ce qui concerne la biopsie rectale.

(3) On essaye de faire correspondre l'image cardiaque présentée par l'examen clinique et l'examen nécropsique, en tenant compte en particulier du rare bloc cardiaque entraînant une dissociation auriculo-ventriculaire du type $2 / 1$ et une hypertrophie cardiaque. 